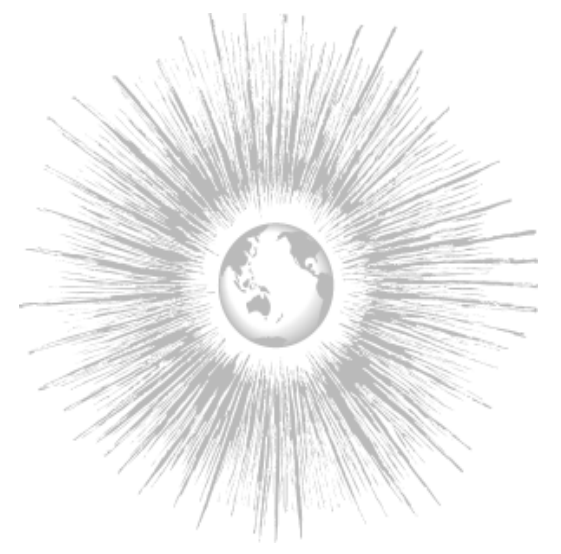

ABSTRACT:

This article considers capitalism as a dis sipative system, developing at the expense of exporting disorder into two sorts of 'environ ment': the physical ecosystem; and a subordinate area of society which serves to nouris mainstream order without experiencing it benefits. Particularly significant is the relationship between the two forms of dissipation. The paper begins by assessing the dangers of translating systems theory into social relations, concluding that the project is neverthe less worthwhile, provided that exploitation and struggle are constantly borne in mind. Explo ing the concepts of 'core' and 'periphery,' the paper highlights the contradictory nature of an attribute of chaos which is both ascribed to the out-group, and also really exported to it. If the core's growth merely destroyed periph eral order, the entropy of capitalism would be starkly exposed in the form of an exhaustion of future room for maneuver. This problem can be kept at bay by maintaining a self-reproducing 'low' order within the subordinate socia system; however the fundamental entropy is still there, and will sooner or later manifest itself in the shape of threats to the sustain ability of that subordinate system. At the leve of the international political economy (IPE), this dialectic unfolds against the background of a 'lumpy' development whereby (following structural crises) order can be reconstituted but at a cost which must be absorbed some where. In the case of the post-World War I reordering, this cost was massively exported to the physical environment. Since a high level of ecological depletion now appears permanently embedded within the capitalist IPE, future major efforts of order-building cannot rely on this dimension to the same degree, and must instead access some new forms of dissipative relationship with the social environment. The paper argues that this is the fundamental significance of the 'sustainable development' discourse: it brings together the physical and social environments into a single approach, where substitution between one and the other can be experimented. To some extent, the social environment can be treated as 'fuel,' and contemporary management systems are noteworthy for exploring the access to an added value through the self-exploitation of small producers, realized through emergent process such as production chains. But ultimately, the 'fuel' definition cannot be separated from the other definition of dissipa tion, the export of disorder; and this must be managed somehow. The dominant interests respond by means of social engineering in the periphery, for example by pushing the sustainbility notion in the direction of social development theories like 'sustainable livelihoods.' Most immediately the problem appears in the form of purely negative phenomena: namely unmanageable levels of poverty and conflict. But there is another issue, even more threatening to the capitalist order, but hopeful for those critical of it: the increasing likelihood of unco-opted forms of emergent social order.

\section{The Interplay between Social and Environmental Degradation in the Development of the International Political Economy*}

Robert Biel

\section{INTRODUCTION}

The maintenance or regulation of any system necessarily comes at the expense of dissipating disorder into a surrounding system. Capitalism seems to contain mechanisms which cause it to 'overdevelop', and hence to generate an excessive amount of disorder which must be absorbed somewhere. This article will argue that this takes two forms. On the one hand, human society has a physical environment, the ecosystem. Its relationship with this environment should be, and through most of history has been, handled in a sustainable way. But since the capitalist mode of production has taken hold of society, it has subordinated this relationship to its own demands and is developing in a way which clearly undermines the integrity of this surrounding system. Secondly, looking within society,

\section{Robert Biel \\ Development Planning Unit \\ University College London \\ 9 Endsleigh Gardens \\ London WC1H 0ED \\ United Kingdom \\ r.biel@ucl.ac.uk \\ http://www.ucl.ac.ak/dpu}

* This article is dedicated to the late Mark Jones. In discussing my book The New Imperialism (Biel 2000) shortly before his death in 2003, he pointed out the need for a fundamentally improved understanding of the relationship between imperialism and the environment. I began to attempt this in a preliminary way in a new chapter for a forthcoming second edition of that book, which focuses on the international politics dimension, namely the current militaristic and repressive phase which I consider as an irreversible response to the entropy in capitalism. In the present paper, I have left aside the international politics aspect in order to concentrate on developing the theory which underlies it. I am grateful for the referee's comments on the first version of this paper.

JOURNAL OF WORLD-SYSTEMS RESEARCH, XII, I, JULY 2006, IO9-I47

bttp://jwsr.ucr.edu/

ISSN $1076-156 \mathrm{X}$

(C) 2006 Robert Bie 
although in one sense the social space as a whole is under the sway of capitalism, this always presupposes a division into one area which appropriates the benefits of order, and another which pays the price. This division can be understood in several ways: at a gender level, at a class level, in the North-South divide, in regional disparities and increasingly in various forms of the marginalization and exclusion of an out-group. In this article, I loosely use the concept of core and periphery to characterize such relationships, and argue that these relationships are also dissipative ones.

This general picture makes intuitive sense, but leaves many unanswered questions. For example, to what extent can we legitimately transpose ideas from physical systems into social ones? If we are to make such a transposition, what is the relationship between structure and agency in the way systems operate? Can we give a coherent definition to the concept of regulation, employed in both physical and social sciences but seemingly without much consistency between the two? And what is the equivalent of entropy within the capitalist mode of production?

This article aims to map out the terrain. It seeks to aid future research by giving more complete formulations of these and similar questions, and wherever this is necessary for the purposes of its main argument, to propose tentative answers to them. The main thrust of the article is to consider an issue of outstanding importance for the current and future world order. Assuming that these two forms of dissipation exist, how does the mode of regulation of capitalism handle the relationship between them? Can it, for example, sidestep limits in the absorption (carrying capacity) of one sphere by augmenting that of the other? This enquiry will involve us in a close examination of the workings of the mode of production. We will be operating with the fundamental approaches employed in the Marxist tradition, but aiming to examine them in a fresh way by using the systems perspective.

\section{THE ENVIRONMENTAL COST OF ORDER}

According to the Second Law of thermodynamics, a system, left to itself, will not move toward higher order; instead, its entropy will tend to increase. If it is to defy this restriction, it must do so through a 'dissipative' relationship with a surrounding system, which constitutes its environment (Kay 199I): order-building is compensated by an increase, within that environment, of a disorder which is in some sense its negative reflection.

For the human social system, this most obviously occurs in our relationship with the physical environment. Any striving for higher order-expressed as 'development' - must be dissipative; but it may or may not be sustainable. This distinction is important. A social system fuelled essentially by solar energy is dissipative because its order is compensated by the degradation of the sun, but from a practical point of view the extremely long time scale means that it can be considered sustainable (Georgescu-Roegen 1975). This is in fact the only meaningful definition of sustainability.

Social development may depart from this sustainability criterion. The basis for such a possibility is that society does not principally interact directly with the solar system, but rather through the intermediary of the earth's ecosystem, which processes and filters solar energy. We can define as unsustainable any development of social order which is fuelled by the degradation of this environment (of the ecosystem itself, rather than of the sun). Such degradation can be illustrated under the following forms:

(a) The plant and animal populations which embody solar energy in a socially useful form could be consumed - or (of particular significance in the contemporary context) manipulated -in a way which undermines their reproduction, or their interdependent systemic relationship to one another.

(b) Non-renewable deposits of so-called 'natural resources' can be conceptualized as a form of 'negative entropy' or 'exergy' (Dincer 2002), converted into entropy as they are used up. Any development primarily fuelled by these will exhaust itself.

(c) The ecosystem has developed self-regulating mechanisms, most importantly for the regulation of temperature. Development could take a form which undermines these.

A social system would be inherently unsustainable if its own characteristic systemic processes developed in such a way as to undermine those of the ecosystem. It seems probable that capitalism has done just that. Let us consider the form that this could take.

It is reasonable to argue that the key driving principle of contemporary society is capital accumulation, and this has been recognized to have implications for creating unsustainable levels of entropy (Prew 2003). The most basic explanation of this is that accumulation has the characteristic of a positive feedback loop. Positive feedback describes any process where the result amplifies the original cause. This property can be utilized creatively (in acoustics, it is utilized with the electric guitar, for example), but there is always a dangerous aspect in positive feedback because it can initiate runaway processes. The accumulation of wealth has always implicitly carried this risk (a certain amount of wealth conveys the power to accumulate more, and so on); traditional society developed counteracting mechanisms to prevent this overwhelming all other social criteria (Biel 2000), but with capitalism, these safeguards were removed. Economics often 
Figure 1 - The Two Levels of Dissipation

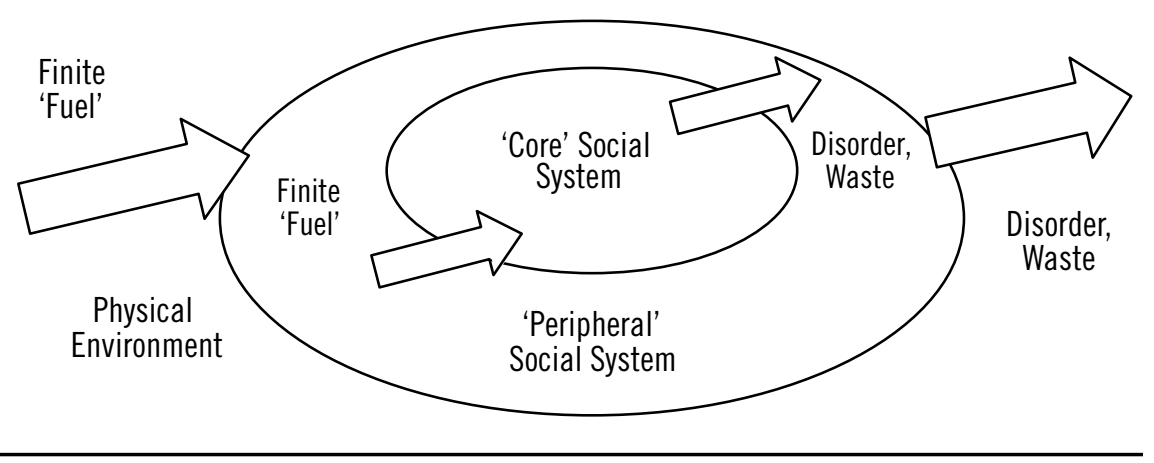

pursues 'self-sustained' growth, which is presented as a desirable goal, but the systems perspective would dissect this notion critically. The image is partly true, but it is precisely where it is true that it is most dangerous: the dynamic of positive feedback loops is indeed self-sustained. The false aspect is the assumption that growth sustains (nourishes) itself from itself, whereas in reality it depends on an environment to degrade. A classic of the environmental literature, the Limits to Growth (Meadows et al. 1972), although mechanistic in some of its attempts to apply systems concepts (notably with respect to population), had the underlying merit of recognizing that capital accumulation would inevitably enter into contradiction with the ecological systems which support life. Much of the subsequent history of mainstream environmentalism has been dedicated to obscuring this dangerous truth.

Whatever its implied feedback-generating qualities, wealth cannot by itself accumulate: it requires social conditions. So far, we have assumed that the only dissipative relationship is the one between society 'as a whole' and its external physical environment. We could indeed theoretically imagine a society which is unified internally, but develops at the expense of unsustainable physical environmental degradation. But this is not applicable to the case under consideration; for it is intuitively obvious that the accumulation feedback loop is premised on division within the social sphere.

I will therefore take the fact of social division (at several different levels) as fundamental, and on this basis will posit, as the main focus of this article, the idea that such internal relationships are also dissipative. This model, which will provide a point of reference for our subsequent discussion, is set out graphically in Figure I. Here, one form of dissipation/degradation is embedded within the other.

In Figure I, order in a useful sense-experienced as stability, predictability, equilibrium or development-is established only within part of society. The remainder operates as a social environment, from which the core can extract a kind of 'fuel' or to which it can export disorder.

\section{PROBLEMS IN TRANSLATING SYSTEMS CONCEPTS INTO THE SOCIAL SPHERE}

The implication here is that the key concepts of the systems approach-the 'cost' of order, dissipation etc.-are in some sense applicable within the sphere of social and productive systems. There is much interesting potential in such an approach, not least in pursuit of a unified view of the ecological and socioeconomic parameters of capitalism, perhaps in finding a common language whereby one could integrate contributions from several different disciplines as part of such a project.

However, the issue of translating systems terminology into human social systems is fraught with difficulties. I will argue that this is not a reason for not attempting it, but it undoubtedly requires a consciousness of the pitfalls. A comprehensive examination of such problems is beyond the scope of this article, nor would it necessarily be the most fruitful idea to attempt this in the abstract. What we are attempting here is rather to examine the systems approach by applying it concretely to a particular problem, thereby hopefully demonstrating that there is something of value in the project. It will nevertheless be helpful at this point briefly to indicate some of the pitfalls and how they could be avoided.

The big potential danger seems to arise when we objectify systems as entities with their own propensities. It is true that this is not really our main aim: it is perfectly valid to focus our attention on certain explanatory tools of systems theory such as the notion that order in one part of the system is in some sense reflected in disorder elsewhere. Nevertheless, it is hard to explore this without impinging on areas such as the notion of systems generating their own modes of regulation (including feedback processes); of phase transition between one largescale structure and another; and of emergence as the self-creation of order. It would be naïve to suppose that we could address such questions without at some point confronting the objectification/propensities issue, and making explicit our stance.

The first thing to be conscious of, and to demarcate ourselves from, is the reactionary usage of the notion of objectified systems as a justification of the status quo. In a sense this is characteristic of the whole history of liberalism: Adam Smith's notion of a 'hidden hand' says that, out of the pursuit of individual acts of self-interest, arises an order superior to anything which could be created by conscious intervention. More recently, Hayek's (1973) position, which forms one of the bases of contemporary neo-liberalism, pushed this in a structuralist direction, to produce a notion of spontaneous order. These perspectives 
supplemented the religious justifications of the status quo employed by earlier exploitative systems, their function being therefore perhaps primarily ideologi$\mathrm{cal}$. This is not to downgrade the importance of the ideological dimension. On the contrary, the embedding of the mode of production within belief systems is fundamental to its functioning. But in emphasizing the deceptive aspect of the systems perspective, we risk losing sight of an important and less obvious dimension: capitalism really operates as a system, and its theories may benefit from recognizing this fact. The market is in some sense an efficient mechanism of exploitation, precisely because it enables exploitative relations to self-engineer themselves. Arguably, it is one of the intrinsic rules of capitalism as a system, without which it would cease to be what it is. The systems concept applied to the market can therefore be regarded as part of a body of knowledge which reflects real-world issues, but which is developed one-sidedly and thereby 'anchored' in the interest of the ruling establishment (cf. Lenin I96I [1915]: 363).

As well as generally presenting the market as the solution (rather than as the problem), the liberal discourse also serves the status quo by concealing important elements of the really-existing system. It keeps quiet about predatory corporate interests which function to channel the value generated by the self-engineered exploitative relations of the market sphere, and about the crucial role of the state in backing such interests. But capitalist self-reflection cannot afford totally to ignore these important aspects. Consequently it has increasingly supplemented its market-fundamentalist facet with a systems perspective on issues such as governance. Here too, there is a strong aspect of ideology: the whole notion of globalization serves as an umbrella concept to justify any aspect of the status quo as an inevitability. But the recent debates also address real issues of the mode of production and indeed perhaps, by monopolizing the terrain, inhibit a more radical and critical use of systems theory to analyze them. The key weakness of market-fundamentalism was the assumption that all relationships are transient, whereas the real world witnesses emergent structures at a number of levels. One of the major developments of capitalism over recent years has been to take this on board: industrial clusters, the notion of 'network capitalism' (cf. von Tunzelmann 2003), and so on. But of course this is used in such a way as to inscribe these developments within a fatalistic subservience to global accumulation processes, to foreclose the debate about alternatives or about radical adaptations of such processes. It is all too easy to make a transition from sound thermodynamics to dubious social theory (for example, Wall 1993) if one forgets the manipulative dimension of current management doctrines.

We can convincingly argue that the pro-status quo usage of the systems approach is foreign to the essential nature of that approach, in the sense that the latter is inherently open-ended and non-teleological. This suggests that to a certain extent we could conduct a critique of the establishment discourse from within the realms of systems theory itself. Nevertheless, such an approach would obviously not be adequate. In this article, our main working rule of thumb has been not the abstract logic of systems theory, but rather the reality of exploitation and struggle within social systems as they really exist. It is precisely because the systems approach (as applied to human systems) does not inherently encompass this dimension that it is open to abuse, and therefore that the dialogue with Marxism is important in strengthening and improving it.

While the foregoing argument has emphasized the distortions emanating from the pro-status quo forces, a second, and in a way converse, danger is the incorporation of excessive structuralism within left-wing perspectives. Mechanical materialism, determinism and linear views of development, although (as I certainly believe) foreign to Marxism's basic nature, have historically demonstrated a strong propensity to develop within Marxist-inspired currents of thought. Might not the dialogue with systems theory make this worse?

I will hope that the present article will show that this is not the case, and that the open-endedness of the systems approach is in fact an antidote to some of these risks. Without anticipating the subsequent argument, it is sufficient to raise the issue of the structure-agency debate within social science, and more particularly the issue of the correct attitude to structuralism. Structuralism has a strong tendency to reify systems and their 'propensities.' If we consider its expression in anthropology (for example, Levi-Strauss 1958), it seems clear that there are strong Eurocentric and gender biases in the way the propensities are defined, and it underestimates the importance of agency, most crucially of struggle (cf. Biel 200o). Despite this, I would argue for a progressive potential in some aspects of the structuralist approach. It seems correct to be sensitive to the notion of capitalism as a system with its own momentum, in fact a highly destructive one, a perspective which is certainly present in Marx's work; as such, the system develops self-preserving and self-regulating characteristics, a recognition which is surely central to the contribution of Gramsci.

To recognise this fact does not necessarily involve an over-emphasis on structure as distinct from agency. As I will argue below, although the concept of 'emergence' has some relationship with that of 'spontaneity', it can be defined in such a way as to be fully open to the importance of conscious, intended action - and crucially, action not just by an elite but arising from the grassroots. The systems approach, in its emphasis on information, is capable of suggesting a new perspective on the structure-agency issue. The objective means of regulation within biological systems is the exchange of information, and, as Roederer (2003) points out, in the case of human systems this includes information about the future.' We can relate this to a particular slant on the question of 'agency' - that 
is, the envisaging of desired outcomes-which therefore in a sense becomes the mode of operation of structure. Of course, within the mainstream discourse the systems perspective is currently imprisoned by a narrow framework which recognizes only the market as a conveyor of information; but if this narrow limitation is overturned, the emergent structures produced by information-flows, such as networking, could be broadened outwards as a principle of a new social order rather than being constrained into the role of generating efficient exploitative structures within the current one.

\section{A SYSTEMS READING OF THE CONCEPTS OF CORE AND PERIPHERY}

Following this brief discussion, we can consider the application of the systems perspective to the international political economy (IPE). A useful starting point is a concept drawn from an area of the literature which has already approached relations in the IPE in core-periphery terms: namely dependency theory.

There is an interesting contradiction underlying the whole notion of dependency. It is the core that is really dependent upon the periphery, because without the latter's inputs, or role as a sink, core order would be impossible. But in social systems, the core's dependence tends to be concealed; the official rules of its order typically make the relationship appear to be the reverse, as though the periphery is dependent on it. Gender studies has made a crucial contribution to understanding this issue: the public sphere, where the rules of order are debated, defines these rules in such a way as to conceal official society's dependence on the household (Hartsock 1983). Under capitalism, while the household constitutes a fundamental basis for the supposedly self-sustaining circuits of capital accumulation, it has typically been excluded from the visible expression of that accumulation, as we see in the exclusion of women's labor from the definition of gross domestic product which forms the basis of national accounting (Waring I989).

In a theoretical sense, the core's very identity is dependent on the area from which its boundary separates it and which determines what it is not (cf. Zwick n.d.). This is implied in the philosophical principle "every determination is negation," or in the form developed by Hegel (1969: 528): "What something is...it is wholly in its externality."

Since the core defines itself as a negation of its periphery, an important issue arises in relation to the notion of chaos and disorder. As with dependence, there is a duality and contradiction in this notion. The supremacy of the core is asserted by vaunting its own order, achieved through the ascription of negative characteristics to the outsider. This can be studied in the literature on exclusion: the out-group's identity is manufactured as a representation of all the disorder the core purports to have abolished within itself (Sibley 1995). We can observe this in concrete cases, for example the phenomenon of gated communities (Barry 1998). And in the literature on colonialism, it is clear that the core creates an invented (disordered) 'other' to fuel its own self-identity (Cesaire 1972 [1955], Curtin 1965). Colonialism is an act of expansion, not in the sense of the core admitting more regions to its own order, but of expanding the area within which the manufacture of identities is conducted on its terms. The assimilationist promise is therefore one of an illusory inclusiveness (Fanon I965 [196I]). We can consider today's globalization discourse in a similar light: aggressively 'inclusive', but the very act of inclusion necessitating an act of homage to an imposed set of values. In all these processes, the periphery receives false attributes of chaos, so as to justify the imposition of order. In fact, the excluded experience implies a special definition of order; instead of stability or security, it signifies control.

But this ascribed chaos also becomes a self-fulfilling prophecy: the rise of core order is really reflected in an export to the periphery of a disorder which negatively reflects the order established within the core. In the colonial context, when resources were siphoned to lay the physical basis for core development, the old functioning social order was destroyed without being replaced by a systemically coherent alternative (Rodney 1972). The resultant situation of depleted order could be assessed, for example, by indicators such as poverty and conflict. One of the first to describe this relationship, in what can be considered a significant and underrated contribution to a systems reading of IPE, was Dadabhai Naoroji (1962 [190I]), who explicitly viewed poverty as an expression of 'drain', of a depletion suffered by the colonized country, a siphoning of the material basis of order initially from the hinterland into the extraverted port-economy, and then internationally. Such clarity is anathema to contemporary mainstream poverty discourses.

The relationship between any system and its environment can be conceptualized not just as the export of disorder, but also as the fuelling of the core system from its environment. Since we are dealing in our model with two embedded processes-social fuelling embedded within physical-environmental fuellingan extremely important issue arises in this context. We could confine the fuelling issue purely within the social sphere (bounded by the outer oval in Figure I depicted earlier). In this case the fuelling would be based on human resources. This is a highly significant dimension, whose importance was illuminated by the radical Black perspective in its treatment of the slave trade (James 1980 [1938]). But it is at the same time evident that the core's control of its social environment (periphery) also confers access to resources from the physical environment, situated in or managed by that periphery. In other words, the control of one environment (the social) confers that of the other (the ecosystem). Again, the gender literature has contributed decisively in pinpointing this relationship, notably in 
Carolyn Merchant's (1990) 'death of nature' thesis: the destruction of women's autonomy in early capitalist society removed the restriction on manipulating the genetic resources of the plant and animal populations over which women used to act as guardians, and on access to the mineral resources which earlier taboos had shielded within what was considered the womb of the earth-mother. In the North-South context, the relationship is empirically obvious: the supposedly self-reproducing accumulation circuits in the core are dependent upon the supply of cheap cash crops or minerals. These exact a cost not only in the depletion of the human resources used to produce them, but also in physical environmental degradation (for example, in the case of cash crops, by causing soil erosion or lowering the water table). In Stephen Bunker's (1985) work, a significant contribution to viewing the North-South relationship in explicit systemstheory terms, the social and physical-environmental aspects of the degradation of the periphery are virtually inseparable.

These contributions can guide us towards a very important level of analysis, in the sense that they posit the existence of a close relationship between the two forms of degradation outlined in Figure I, but they still leave unanswered questions about what that relationship is. In particular, Bunker's model implicitly assumes the two forms of degradation to be necessarily positively related, but this would still need to be demonstrated.

We can indeed conceive of systemic mechanisms which seem to bind the two together in a mutually-reinforcing relationship. Since exchange is both an economic category and a thermodynamic one, it may be possible to construct models encompassing both. Hornborg (200I) has provided an interesting illustration of how this could work, and in particular how it could continue or become intensified in a post-colonial context. In thermodynamic terms, the act of production is really one of depletion or lessening of order, because it converts exergy into entropy (cf. Wall I993). But because manufacture fictionalizes this act as one of creation, the value attributed to the finished product is greater than that of the raw materials which went into it. Goods manufactured in the core (the North) can therefore be exchanged at high prices for raw materials exported from the South at lower prices, which in turn permits access to an increased quantity of resources to fuel the next circuit (Hornborg 200I). It is clear that this can be represented as a feedback loop, mediating the depletion of the physical environment through a North-South social relationship.

We could consider in a similar way another important category which spans thermodynamics and social relations: to wit, power. As Gale (1998) has pointed out, in both cases, power can be understood as a capacity to produce effects. Now, here too it is not difficult to construct a model of a feedback loop. Socio-political power confers control over resources (the source of thermodynamic power), which in turn augments socio-political power. Such a perspective could open the way to realizing the project sketched out before his death by Malcolm Caldwell, a pioneer of the concept of linking entropy with international politics (Caldwell n.d. [1972]).

The above mechanisms are extremely interesting. But, despite the strength of this demonstration, I will nevertheless argue that we should be careful to regard the physical and social forms of dissipation as distinct categories, precisely in order to study a relationship between them which may undergo important changes. My central argument in this article will propose a model which goes counter to any simplistic assumption of a positive relationship between the two forms of degradation. In fact, the mode of operation of the capitalist IPE could include compensating movements of the two categories. Both would continue to be depleted, but not necessarily at the same rate.

Such changes form the basis of what I will call regulation. As a prelude to defining this concept, the next step will be to make explicit our understanding of a key idea which underlies the disorder/fuelling issue, and in particular the limitations and constraints imposed on a system's capacity to export disorder or import fuel, namely entropy. The question is, can this be defined in a specifically social sense?

\section{A SOCIAL DEFINITION OF ENTROPY}

Entropy as an idea is somehow linked to the exhaustion of the future room to maneuver, or of the developmental potential, in any system. The latter fuels itself not only at the expense of physical resources (raw materials, human resources), but by depleting its future room to grow.

An important point of departure for our argument can be found in the work of Rosa Luxemburg. In The Accumulation of Capital (Luxemburg 1952 [1913]) she argues that the apparent self-nurturing of the accumulation circuits is secretly fuelled by an environment (within society) which it progressively degrades (the German text employs the French word 'milieu,' rendered in English translation as 'environment'). Luxemburg (1952 [1913]) expresses the relationship as follows: "The existence and development of capitalism requires an environment of non-capitalist forms of production..."; "Accumulation is more than an internal relationship between the branches of capitalist economy; it is primarily a relationship between capital and a non-capitalist environment"; and it fuels itself from the "progressive breakdown and disintegration" of this sphere. Employing this model, we could represent entropy as the shrinking of the remaining area available to support core order. Concretely, Luxemburg defines the milieu as 'tradition,' the area of society not yet part of capitalist relations. As it is broken down, it is brought, not into the core itself, but into the sphere of commodification, of 
monetary/exchange relations; and the more this happens the less is available to degrade in the future. The entropy of the core is thus expressed in its expansion into the territory of its future room to develop.

Let us look closer into the implications of this argument. In terms of the model set out in Figure I, the milieu would be the region between the two ovals. The pro-capitalist definition of 'growth' would see the core enlarging as the benefits of capitalism spread, in proportion as the traditional milieu shrinks. This is logically consistent but totally at odds with reality: whatever peripheral areas, for example 'Newly Industrializing Countries,' may be admitted into the club of developed countries (if we accept at face value the most optimistic assumptions of mainstream development discourses), their contribution is surely outweighed by the increase of exclusion within their own borders, and indeed within those of the historic core. The radical perspective can respond to this flaw in the simplistic 'growth' model, because the notion of accumulation immediately supplies a more precise and convincing definition of 'growth': the system requires to grow, in the sense of its expanded reproduction, simply in order to continue existing, without any assumption that the region which benefits from its order would expand. The core's demands therefore grow, not only threatening to outstrip the physical environment's ability to supply raw materials or absorb its wastes, but also imposing a certain 'footprint' which the social milieu cannot indefinitely support.

This makes sense of real events, but there is a logical problem in understanding what happens to the region where the old order is destroyed, but seemingly not replaced by anything. In this context, it is interesting to consider the dependency literature. I970s dependency theory recognized the seminal importance of Luxemburg's work (Frank 1979), while diluting this to a certain extent by considering the contribution of this external sphere to accumulation as being somewhat secondary (Frank 1978: chap. 7). This conflicted judgment reflects a real problem, but does not necessarily answer it in the correct way. I would argue that the central merit of Luxemburg's contribution is that she posed far more clearly than anyone else the notion of entropy-in the sense that each moment of development exhausts the capacity for future development. The dependency approach did not really grasp this fact, but on the other hand it made a crucial step forward by addressing the unanswered question, namely what replaces the old (traditional) order in the periphery: in effect, the answer is a depleted or 'low' order, which is an order, but not the same as that in the core.

Let us seek a logical framework for interpreting this notion. In a mechanical reading of Luxemburg's model, two assumptions would be made. Firstly, tradition would be a social equivalent of exergy, a fossil fuel laid down over millennia. There would be an 'arrow of time', because for practical purposes tradition (equivalent to the image of a broken glass, often used to illustrate the progression towards greater entropy) could not reconstitute itself. Secondly, the boundary between the commodity economy and still-pristine tradition would be a 'hard' one. Social forms could exist in only one or the other state, not in an intermediate state. But neither of these assumptions is necessarily true. Empirically, such a realization can already be seen in the work of Paul Baran (1973 [1957]), which showed how elements of tradition, wrenched from their old self-reproducing systemic structure, become incorporated into a new kind of peripheral structure. Dependency theory went further with its concept of the articulation of modes of production within a complex social formation, which may include elements of different modes of production under the auspices of a dominant mode (the capitalist monetary economy). Making a systems-theory reading of this notion, we can now understand that the social fuel includes not just tradition in some static sense but a whole 'parallel' economic structure, which is not merely depleted, but has faculties to reproduce itself.

It can be remarked that this order is established not just passively but rather, as we might expect in human systems, through an element of agency-more specifically of negotiation. As an illustration, we can highlight the aspect which is mediated through the international system. We can see in Dos Santos' (1970) classic formulation of dependency that the periphery is somehow exploring its structural relationship to the centre, and this can be given graphic form in a model derived from South Korean dependency theory (Kim 1987) (Figure 2). If we translate this into systems terminology, we can understand some of the implications which dependency theory was unable to make explicit. 'Backwash' can be equated to the drain, the aspect which purely destroys order. The 'progressive' social forces (the entrepreneurial elites in the periphery) are seeking to negotiate the conditions of the depletion of their own social fuel (tradition) in such a way that a point ' $\mathrm{p}$ ' is attained where some order spreads, although still of a depleted type. This ongoing process of negotiation in turn builds order at an international-systems level. It creates a certain basis for stabilization, for the selfperpetuation and self-regulation of core-periphery relations, but without removing the fundamental entropy.

This negotiation has to do with the transition from the order-destruction associated with colonialism, into the emergence of the postcolonial peripheral order. All of these elements-the low order described by Baran, the equilibrium point between core and periphery interests implied by Dos Santos' model-are ways of forestalling the entropy which was posited in an unrealistically stark form in Luxemburg's theory.

We can go further, in saying that peripheral systems are not just self-reproducing in a static sense, but can be arenas of new order-creation, i.e. emergence. We can formulate in the following way a conception towards which the depen- 
Figure 2 - 'Negotiated' Order in the Dependency Model

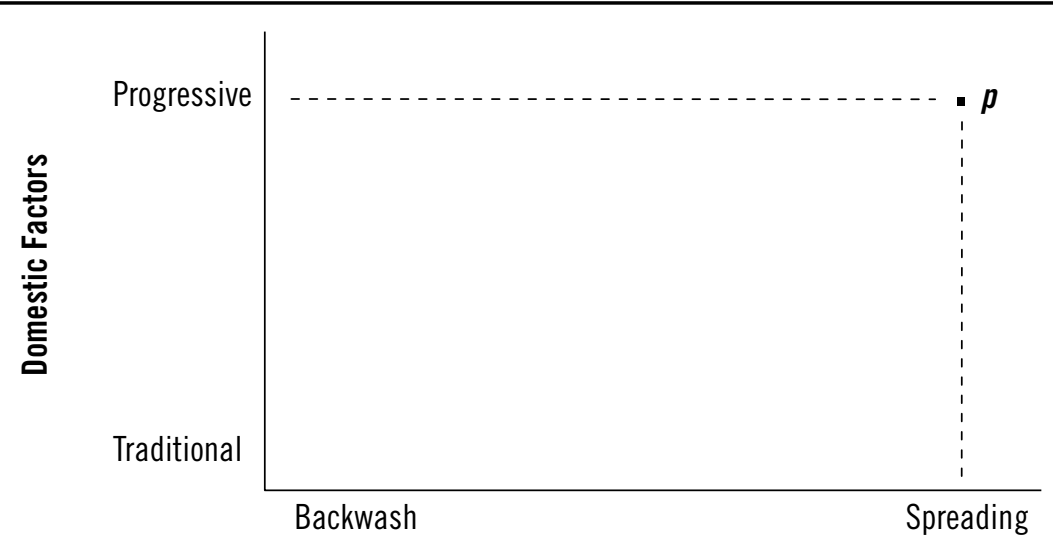

International Factors

Source: Adapted from Kim (1987)

dency literature seemed to be striving without quite being able to attain: dependence is a way of channeling emergence, or prescribing the dominant attractor which gives it shape, subsuming peripheral emergence within the demands of core stability. The term 'co-opted emergence' can be used as a concise expression.

At the same time, the entropy is definitely only forestalled, not abolished: each episode of relative stability is achieved at the expense of a non-renewable depletion of social fuel. Although in the abstract a human working population should be able to reproduce itself from itself, the whole point of the capitalist mode is its tendency to erode that faculty; this is surely one of the main things highlighted in the descriptive parts of the first volume of Marx's Capital. Insofar as this problem is partially (though by no means completely) stabilized within the mainstream sectors of employment in the geographical core, for example through Factory Acts, it is exported into the informal sector and the geographical periphery. Once the tendency to disorder has been exported into this milieu, it is dependent on the milieu's capacity to maintain or generate systems-for example, informal networks - to absorb it. Such absorptive capacity is real, but nevertheless limited; it could break down, and then be difficult to reconstitute. This is the reason why the entropy is simply diluted, by exporting some of its effect forward in time. Luxemburg was in the largest sense correct to highlight a finite capacity of the social milieu to fuel the construction of core order; the fundamental point is that instead of a vacuum there is a system, and the spotlight for understanding entropy shifts onto the nature and limitations of that system.
Let us now consider more closely the time dimension within which this entropy would express itself. An important point of contact between general systems theory and the IPE literature is the 'lumpy' nature of a process which develops through a succession of phases, with major 'efforts' of transition between them.

\section{THE DEVELOPMENT OF THE MODE OF PRODUCTION THROUGH TIME}

The Limits to Growth (Meadows et al. 1972), with its exponential model of capital accumulation gobbling up the ecosystem, was invaluable in raising awareness of some uncomfortable general truths about the capitalist mode of production; however, there are fundamental weaknesses which undermine the applicability of this model as a practical tool. We require the contribution of Marxist political economy to show that accumulation does not in fact proceed in a regular exponential curve, but is rather interrupted by periodic crises. According to Meadows' simplistic assumptions, such interruptions would presumably bring a respite for the entropy of the mode of production, but in the light of the issues we have just discussed this is obviously not true: periods of crisis actually witness an intensified depletion of the social milieu, which struggles to cope with an accelerated export of disorder, in the form of unemployment or (in the NorthSouth dimension) a rising 'third world debt', which can easily be shown (cf. Biel 2000) to represent an export of the crisis of the industrial core.

Without addressing the crisis phenomenon comprehensively, it will be useful to highlight the aspect most directly relevant to our argument here. Allowing for significant controversies about many aspects of their definition, there would be some agreement in the field of IPE about the existence of major phases or long cycles. The underlying imperative, accumulation or expanded reproduction, is expressed in specific structures which stabilize themselves for a period, before breaking down and undergoing phase transitions towards new ones.

Are the phase transitions a property of matter itself or of conscious policy? This takes us back to the 'structure-agency' issue, which remains latent within the notion of regulation. As I have argued, any development within human systems involves, as its objective means of regulation, the exchange of information, which includes 'information about the future' (Roederer 2003), the envisaging of desired outcomes. And, in the case of the IPE, development is 'lumpy' because learning is crisis-driven (Byron 200I). Mainstream discourses, severely hampered by liberalism's reticence in recognizing either the temporal specificity of structures, or the various non-market (e.g. governance) structures which give them form, has grappled with understanding such transition, notably through institutional theories, or Keynes' recognition that the economy could exist in a number 
Figure 3 - Overall Decrease, Temporary Increase of Order Through Successive Accumulation Regimes

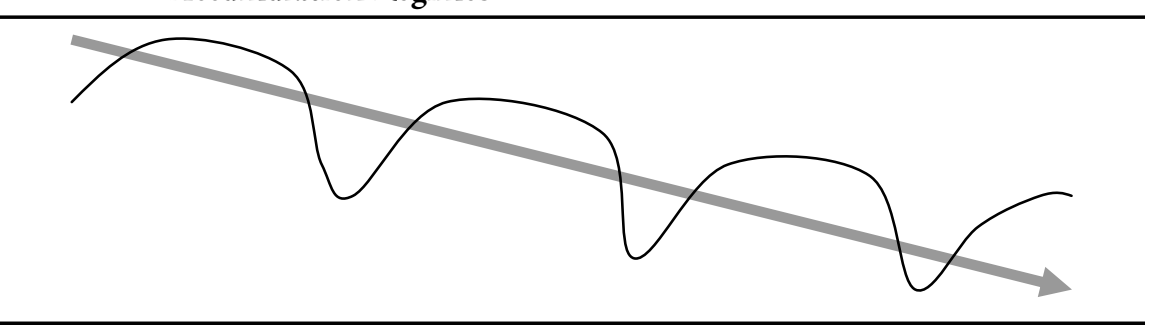

of different equilibria. Most usefully, the French regulation school, albeit not from a clearly articulated systems perspective, supplied the concept of 'regimes of accumulation' (Lipietz 1987). From this perspective, regulation is both a product of a system and a conscious act. A regime is itself a system, with a certain set of key actors who relate according to an emergent set of rules, and which gives concrete expression to the larger system (the mode of production as a whole) during a particular historical phase, for example over a period of about thirty years.

If there is a fundamental entropy, it would manifest itself tendentially in a very long time-scale, as in Figure 3. In the shorter time-scale, where we are considering the life-cycle of a particular regime of accumulation and its transition to the next, we would expect to encounter increases in order. This suggests an explanation of the fact that many Marxist currents of thought have historically been confused by periods of capitalist stabilization (cf. Day 198I).

Let us now represent this wave-like development in terms of real events (see Figure 4).

Our purpose will be to concentrate on the realities of the most recent regime of accumulation, which can be considered to have begun around 1980. But we should first establish its historical context by considering the characteristics and limitations of the one which preceded it. This will enable us to concretize our earlier definition of entropy as the exhaustion of future room to maneuver, of a finite set of development possibilities. These parameters can be concretized in the shape of a certain set of regulation tools, which, once pressed into service, will then not be available as a new input for the resolution of the next structural crisis.

\section{THE SCOPE OF PHYSICAL-ENVIRONMENTAL DEGRADATION WITHIN} THE POST-WORLD WAR II REGIME OF ACCUMULATION

In 1945 there was a very strong element of agency as conventionally conceived (i.e. the conscious designing of a new order), but a discourse analysis would suggest that this was an agency preoccupied with structure. The work of Keynes (I919), a major influence on the 'information about the future' followed at that
Figure 4 - A Visual Representation of Regimes of Accumulation as Alternating Phases of High and Low Order

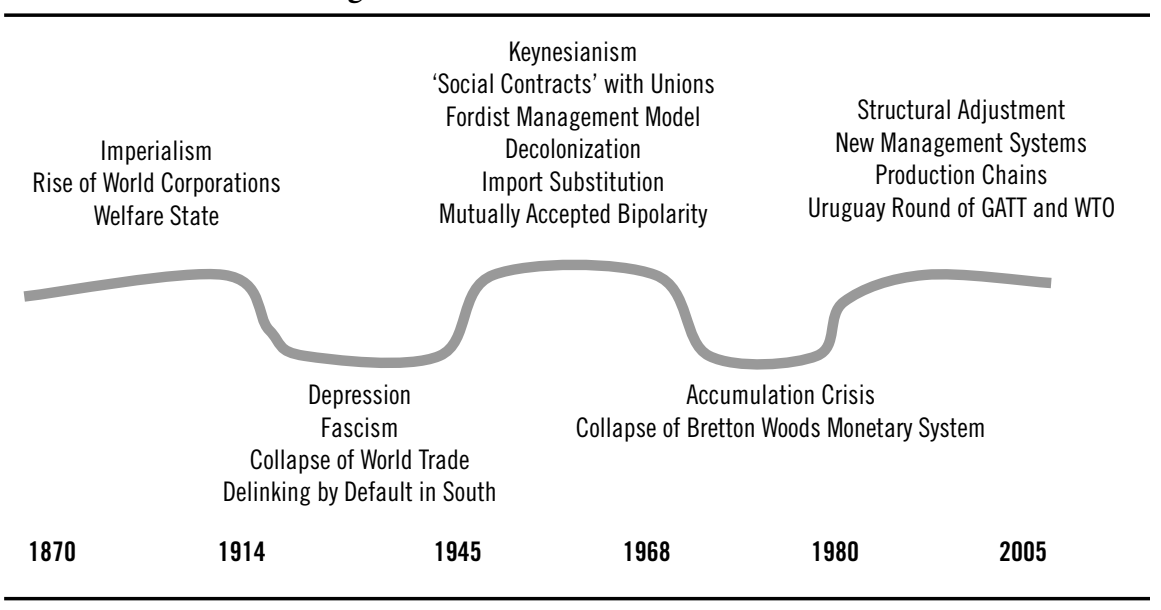

time, was always centrally preoccupied with the conditions of social stability. At the end of World War II, a wider global order was designed to sustain that of Europe and the Atlantic world (cf. Leffler 1994) -which included nourishing it with natural resources located in the physical environment of the geographical periphery.

It should be evident that within a mode of production premised on accumulation there is an ambiguity about the nature of order. If we consider order as structure, then the main 'effort' would be expended at the time of its initial establishment. Once established, order-as-structure means a stable set of effective actors, rules, and relationships which reproduce and even repair themselves within the compass of that regime. This is the reason why in Figure 4 we could represent the periods of high order as a flat 'plateau,' to suggest equilibrium, and self-maintenance, without too much additional cost. On the other hand, orderas-accumulation means that the regime must, throughout its life, incur a rising environmental cost (precisely because of the feedback characteristics of accumulation). For example, the Keynesian cycle (Figure 5) can be perceived in two ways. From the order-as-structure standpoint, it represents a certain politicosocial stability and equilibrium, in the sense that the state, employers and trade unions acquire stable relationships in the form of social contracts, etc. On the other hand, considering order as accumulation, we can easily interpret the same model as a positive feedback loop (see Figure 5).

Figure 5 shows us that there is a continuing cost, which we can seek to represent in physical-environmental terms, for example by the consumption of energy (see Figure 6). 
Figure 5 - The Keynesian Cycle

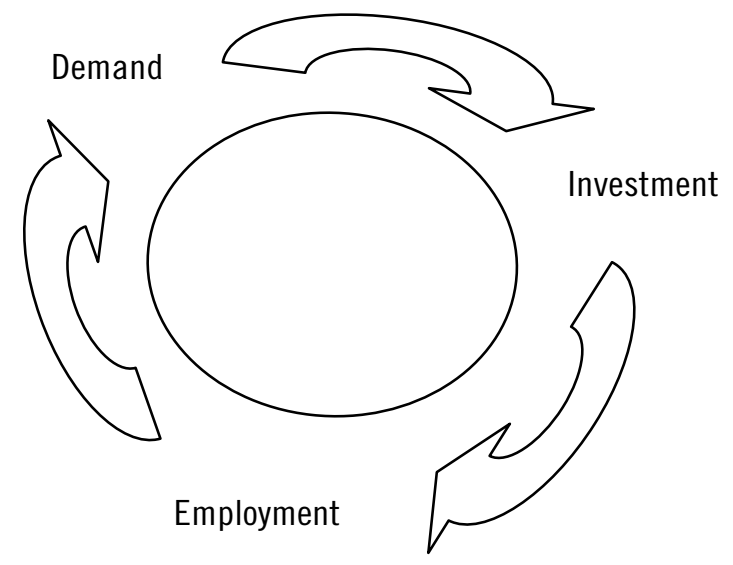

The curve in Figure 6 suggests two reflections. Firstly, the rise of energy consumption in 1945 is so remarkable as to suggest that the post-war regime was fuelled mainly through the degradation of the physical environment. And indeed, although we do not find policy-makers openly saying that the physical environment was being sacrificed for the sake of socio-economic stability, discourses are often as significant for what they do not say as for what they do. Earlier periods of industrial capitalism had in fact been characterized by a strong consciousness of resource scarcity-which drove the whole notion of geopolitics (cf. Sprout and Sprout 1968), imperialism and social Darwinism. The fact that this was suddenly swept aside and replaced by silence constitutes a very strong statement that the objective constraints of the physical environment were being swept aside. Secondly, from the early I980s (by which time the post-war regime may be considered to have come to an end) the curve continues to rise. This suggests that energy degradation had in some sense become permanently embedded within the IPE and would be difficult to reverse through subsequent phase transitions. If this is true, then according to the central assumptions of this article, the effort of establishing new regimes of accumulation (in 1980, and following the next structural crisis, whenever that occurs) would need to find 'something else' to degrade, and logically we would expect this to be some definition of social fuel.

This perception, of a post-war order essentially fuelled by the physical environment, is helpful in many respects. Nevertheless, I will argue that the post-war regime contained also an important sub-theme: in a covert way, it laid the basis for an intensified dissipation into the other, social environment. In doing so, it set in motion processes which remained latent during that regime only to become actualized more recently.
Figure 6 - World Energy Consumption, 1905-2005

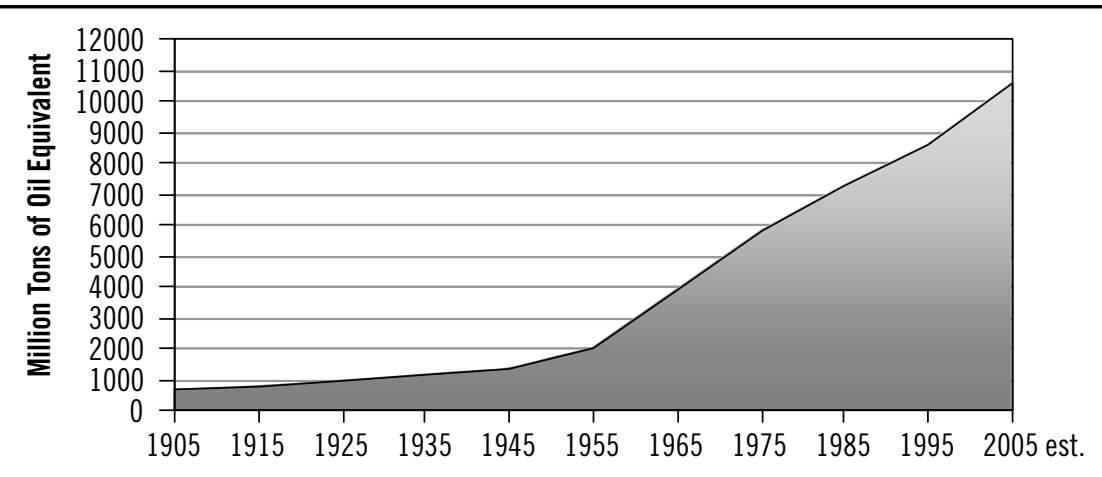

Source of Data: BP Statistic Review of World Energy 2004; Energy Information Administration

International Energy Outlook 2004; Jancovici J-M, I'Avenir climatique, Paris (Seuil) 2002

THE BASIS OF THE 'SOCIAL FUEL' ISSUE IN THE BUILDUP TO THE 1980 REGIME OF ACCUMULATION

Poverty can at one level be considered an indicator of disorder because it undermines the two prerequisites of a stable system: social control (willing acceptance of the order by the lower strata) and consumption. In fact, at many levels of analysis the poor are the periphery: the excluded, subject to high levels of risk, lacking the predictability or stability provided by core order and managed through low, repressive forms of order. On the other hand, post-war development discourses carried an implicit vision of another side to poverty: as a kind of fuel for a developmental process which would eventually eliminate it. 'Growth' would increase the size of the cake available for distribution, but a precondition was the successful completion of a preliminary phase marked by high accumulation (to create infrastructure and machine-building industry), and therefore associated with low mass consumption and high levels of inequality. This is often given graphic expression in the 'Kuznets curve,' whereby the measurement of inequality describes an inverted ' $U$ ', rising in the early phase of industrialization only to fall in the later phases. The Lewis model, a key component in development theory (Lewis 1958) illustrates how, in a sense, poverty itself was supposed to propel this process: the rural poor are progressively drawn away from the (gradually-depleted) traditional sector into the urban/industrial economy through succeeding circuits of expanded capital reproduction, inputting cheap labor until the initial phase of development is complete.

The assumption of such 'stages' models was that more and more countries would join the club of developed nations, the core thereby expanding in size while the periphery shrank. But if it is true that development (under capital- 
Figure 7 - The Kuznets Curves of Two Countries at Different Stages of Development

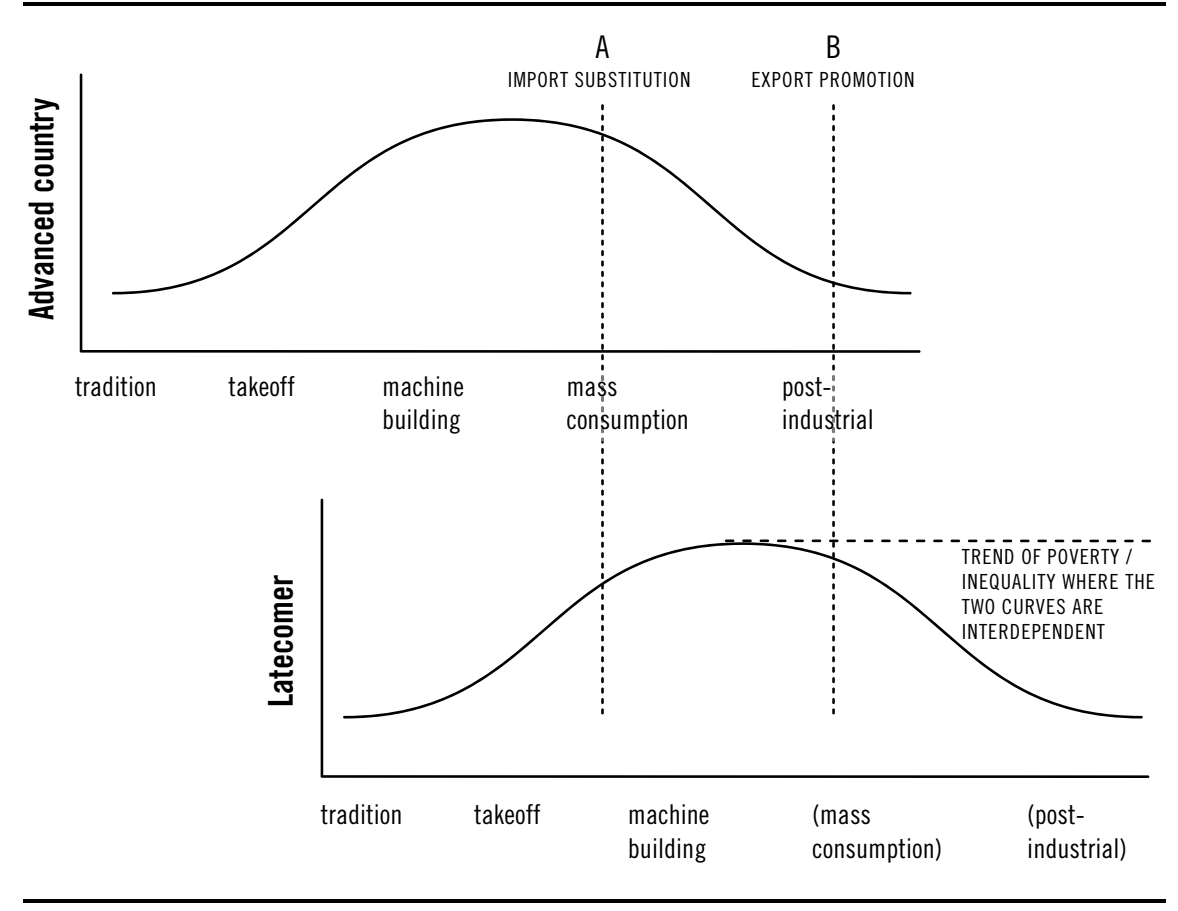

ism) requires a periphery, this reasoning looks suspect. In critiquing this assumption, we can draw upon the treatment of the 'pauperization' issue in dependency theory. Marxist political economy already implied that in some sense accumulation manufactures poverty in and through the process of growth itself. Samir Amin (1977: 35-6) then showed that the tendency to pauperization only manifests itself at the level of the entire global system. Interpreting this from a systems perspective, we could say that the core manages the internal pauperization associated with its own development by dissipating part of it into the South. The claim of the Keynesian revolution to have achieved this on a purely endogenous basis was illusory.

Let us represent this relationship in the form of two overlapping Kuznets curves, plotting the increase and decrease of poverty or inequality against the stages of development (see Figure 7).

If we take a conventional view where the two processes in Figure 7 are isolated and self-sufficient, then the situation at point 'A' (situated, for example in the I960s), where the curves describe opposite motions, simply reflects two different (unconnected) stages of development. However, according to the foregoing argument, we would suspect that poverty in the South in some sense reflects
Figure 8 - Broad Profit Rate: Six Sectors

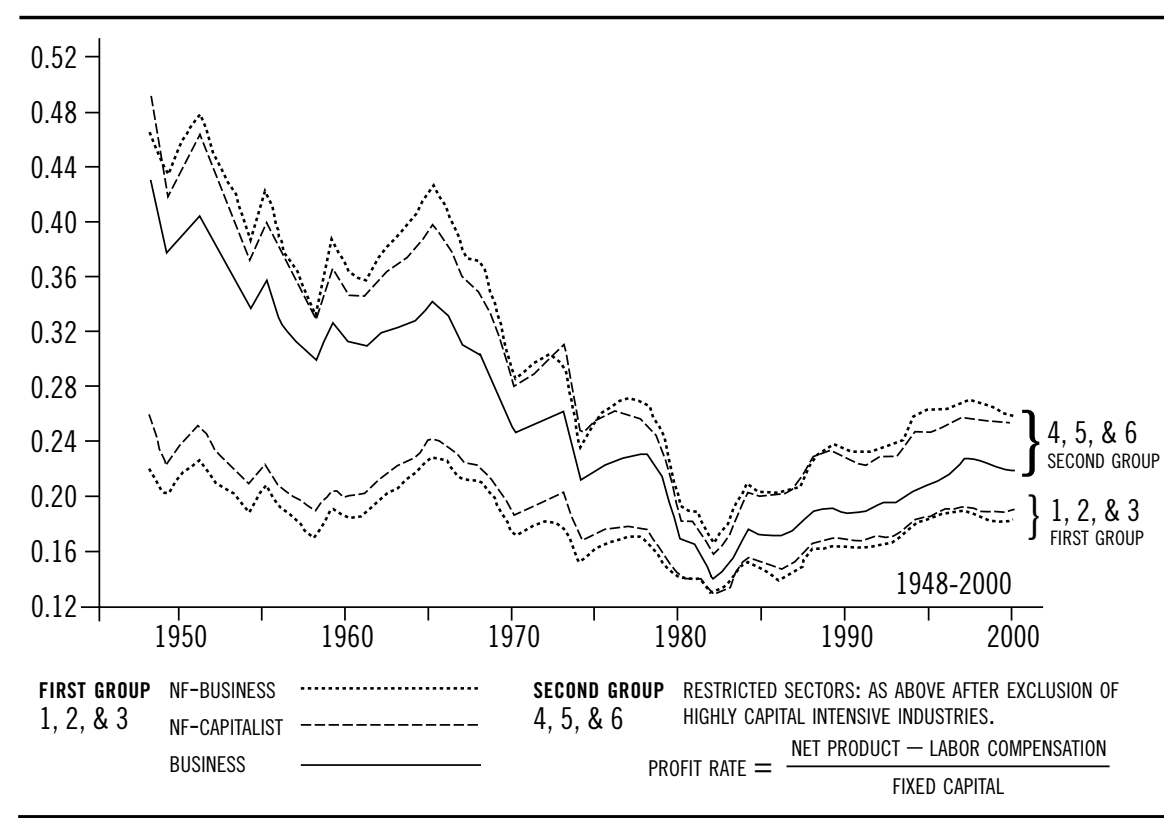

Source: Duménil and Lévy (2000: 443). Re-illustrated by Eric Titolo for JWSR.

the disorder banished from the core; consequently the poverty would in reality represent, not the inevitable cost of an endogenous high-accumulation phase leading to development, but rather a 'draining' of the social resources which are supposed to fuel progression to the next stage. Let us consider how this could happen in practice. At point 'A,' the development of core order (which requires a mass-consumption stage) makes it necessary to expand the mass market, but this has to be compensated by measures to prevent the rate of profit from falling. The periphery at this same moment experiences cheap labor on the basis of its own social fuelling process, i.e. the breakup of traditional society leading to migration to the towns in search of work. If core capital invests in the periphery (for example, through transnational corporations establishing subsidiaries under the guise of import substitution policies), it will gain the benefit of this social fuel and safeguard its overall rate of profit. In this way, the developmental logic of the core imposes itself as attractor upon that of the IPE as a whole (cf. Figure 4), sweeping up the seemingly autonomous peripheral process. Southern poverty begins to become a representation of the global 'drain' process.

The full implications of this relationship becomes apparent when we consider the more recent situation, represented by point 'B' in Figure 7, which comes into force from 1980 onwards. The North will continue to be a high-consuming 
society, but begins to specialize increasingly in knowledge, management, investment etc., rather than in producing the actual goods. It must therefore import the latter. If the periphery, which already has low labor costs, switches to export promotion models, it will be able to supply them. And because the imported goods are cheaper, this will provide an additional boost to the rate of profit of core capital, by decreasing the cost of living. But the peripheral Kuznets curve was supposed to be driven down at this point, on the assumption that endogenous consumption was required. There is now no reason for this to happen, since the market is external. So the situation where high consumption is focused in the core may become embedded within the global IPE, and peripheral poverty/ inequality therefore continues at a high level represented by the dotted line. This could become a sort of mega-characteristic of the IPE, which continues to reproduce itself irrespective of future major changes in the regime of accumulation.

The parameters for a new stage in the capitalist order therefore carry an implied social cost, an embedding of poverty or inequality, which is the true expression of the system's social entropy. The central problem then becomes, how far this can be contained within reasonable limits, prevented from undermining the self-reproducibility of peripheral low order to the point of degenerating into chaos? This question will be a central concern of the remainder of our argument. The extent to which the system is forced to deplete its social environment would seem to depend on the amount of room to maneuver in its relationship with the physical environment.

\section{RELATIONSHIP BETWEEN ACCUMULATION AND ENVIRONMENTAL}

\section{DEGRADATION IN THE TRANSITION TO THE CURRENT PHASE OF THE IPE}

Considering again our schematic model of succeeding phases in the IPE (see Figure 4 above), how could we give a tangible expression to the re-establishment of order around 1980? The primary determinant of order, the reproduction of capital, which was damaged by the crisis of the I970s and needed to be repaired, could be represented by the rate of profit; in Duménil and Lévy's (2000) graph, the notional curve we sketched earlier appears in quantitative form (see Figure 8).

The pattern of Figure 8 looks very like Figure 3 in that while there is an increase of order, it appears to be 'lower' or somehow more 'difficult,' so there is a tendential entropy lurking within it. But we must consider the qualitative characteristics of that new order. The sectors addressed in Duménil and Lévy's study are precisely those where we might expect the entropy to be strongest, since they reflect the oldest areas of the capitalist economy: they relate firstly to accumulation associated with industry, and secondly to industry located in the core itself. The question arises whether the capitalist mode of production could re-invigorate itself by modifying this focus.
Hornborg's (2002) model would imply, as we have seen, that this is unlikely: apparently, these two features will be indelibly imprinted upon the IPE-i.e., to use the terminology we have just advanced, with the status of mega-characteristics which cannot be overturned by a subsequent regime of accumulation. But experience suggests that this is not wholly true. That such a shift in focus, away from the core itself as the locus of industry and to some extent away from industry itself as the driving force of accumulation, was always a latent possibility can be illustrated by the contribution of Hobson (1902) who, at the very beginning of the $20^{\text {th }}$ century, described the two basic conditions for such a shift: one, the rise to dominance of a new form of accumulation not subordinated to industry, i.e. finance capital (at the time he wrote, mostly parasitical upon manufacturing industry, but this would not necessarily always be the case); and two, the transfer of manufacturing to the periphery, specifically to Asia.

Now the crucial question is to understand the implications of such a development for the physical environment. The futurological environmental literature, which raises important issues while not questioning capitalism in a deep sense, accords considerable significance to the concept of 'decoupling' (for example, Raskin 2002). It is interesting to explore this concept in a more radical way. Clearly, if industry remains the focus and all that happens is a change of its location, any 'greening' would be merely cosmetic: for example, pollution of the immediate living environment could be reduced in the core (by shifting industry to the periphery) but without reducing the physical-environmental entropy of the system as a whole. It might well get worse, because of the huge transportation costs associated with globalized industry.

On the other hand, a more profound change might occur if accumulation were decoupled from industry itself, and increasingly linked to non-industrial forms of finance capital. It is precisely the spread of commodification (part of the definition of social entropy which we derived from the Luxemburg model) which seems to create this possibility, by introducing new sectors like tourism, software, the trade in ideas, sports goods, etc. These all have an environmental cost, but maybe not the same as conventional industry. Accumulation would still be coupled to environmental depletion, but not necessarily at the same rate as before.

However, a preliminary view would suggest that this is not what actually occurs. For example, if the new sectors were really less energy-intensive, one would expect energy consumption in the old industrial countries to decline as they become relatively de-industrialized. But some research suggests this is not the case: roughly the same (preponderant) proportion of energy is being consumed in the North today as it was under the previous regime (Podobnik 2002). In the light of our previous argument, a significant interpretation suggests itself: 
the deterioration of the physical environment is coupled to capital accumulation per se, rather than to specifically industrial accumulation. Other evidence would suggest that the main sector consuming energy is increasingly that categorized as 'residential' (World Resources Institute 2003). This might imply that physicalenvironmental degradation is as closely coupled to the 'lifestyle' consumption which propels contemporary accumulation as it was to the primarily industrial accumulation of earlier regimes, and without any significant reduction in intensity. If this is true, the notion that capitalism could evolve into a low-entropy form is illusory, and the curve expressed in Figure 6 could not be expected to flatten significantly. And if this is the case, there would be no leeway in the physical environment to fuel the supplementary effort of establishing and maintaining a further accumulation regime, when this becomes necessary.

It may be objected that by focusing on one of the more traditional areas of depletion - energy consumption - the above discussion underestimates the possibility of finding new aspects of the physical environment to degrade. For example, biotechnology has achieved this by exporting the entropy into the region of risk, the risk of massive hazard. Nevertheless, exporting the problem into the (near) future is not really a solution: recent events suggest that the limits of physical-environmental degradation are precisely manifesting themselves increasingly in the form of massive hazard. This only confirms a strong sense that the problem with capitalism since 1945 is that, with respect to the physical environment, the 'normal' mode of operation is now so intensive that the system operates permanently close to its possible threshold; in the future, the cost of regulation is therefore likely to be increasingly transferred into the 'other' environment, the social one.

I will now argue that the fundamental sense of the 'sustainable development' idea is precisely to find a way of doing this.

\section{'SUSTAINABLE DEVELOPMENT' AS A TOOL FOR TRANSFERRING COSTS TO THE SOCIAL SPHERE}

There is a convincing argument that the unifying principle for the sustainable development' discourse is actually commodification itself.

This thesis appears strange because at first sight it is in contradiction to the intellectual roots which fed into the discourse. The important theoreticians approached the issue of the relationship between market and environment often from different directions: Garret Hardin's (1968) early thesis of the 'tragedy of the commons' was fundamentally skeptical towards the market; Herman Daly in contrast was strongly supportive of the market within its own sphere, but he developed the notion of 'externalities' (employed in economics to express the side effects, in this case negative, of economic decisions) in a radical way, showing how the market can have systemically negative effects (Daly and Cobb 1989). But despite these different points of departure there was convergence in the sense of assuming a conflict between the market on the one hand and the two elements which underpin it: an area of society (community, tradition) which operates according to non-market mechanisms; and the physical environment. On such an intellectual basis, one might have expected sustainable development to become an argument (and set of tools) for curtailing the market.

However, this reckons without the hidden dominance of the economic definition of sustainability (i.e. the reproduction of capital), as an overriding attractor, which tends to subordinate to itself all other forms of reasoning. Thus, what should logically have been an anti-market discourse was surreptitiously transformed into a pro-market one. Typically, this was conducted through the following reasoning: if incompatibility between market and non-market spheres is 'the problem,' it can be resolved by abolishing the latter! This is rationalized in various ways, for example in the argument that if free goods (the freely available environment, the social commons) are all turned into commodities, any activity which affects them (such as discharging waste into a river) will have a cost, which people will be forced to incorporate into their economic decisions.

This line of argument serves, of course, as an excuse for a blatantly profitoriented commodification. As Goldman (2005) points out, it would be a dangerous error to regard the sustainable development agenda as a mere cosmetic exercise; on the contrary-at least in the hands of the World Bank, which contributes decisively as an ideas-factory in generating the dominant form of that discourse -it constitutes a real policy tool, serving precisely to bring natural resources within the definition of capital. But even more important, I believe, commodification essentially became the binding principle in a discourse which for the first time brought together ecological and social forms of entropy within a single vocabulary of regulation. And, as I will now argue, the point is not so much that they are merged within this vocabulary, but rather that a common measure is created through which they can be compared, and most importantly substituted.

Akerman (2003) describes one form of substitution, made possible by rebaptizing nature as 'natural capital.' Here, the physical environment is used to maintain aggregate capital stocks, serving as a fund to draw upon when the reproduction of money capital is deficient. This argument is important, but the definition of substitution is so far incomplete because it addresses only one side of what should be a triangular model. The picture is changed significantly once we incorporate also social capital. Most obviously, we now have a second form of vertical substitution, illustrated in Figure 9, triangle a. But it is immediately apparent that another form of substitution becomes available by shifting the burden horizontally. 
Figure 9 - The Substitution of Natural and Social Capital

[a]

In line with our basic argument we would expect a shift towards the right side of the triangle: the social sphere (Figure 9, triangle b). An analysis of the direction of development within the mainstream sustainability discourse certainly seems to bear this out: beginning in the '70s with a focus primarily on the physical environment, it had by the time of the Johannesburg summit of 2002 metamorphosed to focus at least as much (if not more) on the social dimension. This movement (from left to right across the bottom of the triangle) would be one where the total entropy remains constant, but the possibilities for shifting it around may be important for regulation.

Now, on the basis of our earlier propositions, we can say that the core's dependence on its periphery (environment) takes two forms: the export of disorder and the availability of some kind of 'fuel.' The former aspect simply treats the periphery as a sink. From this angle, the shifting of disorder into the social sphere can be illustrated by the following argument. The notion that the depletion of free goods can be reduced by giving them a monetary value signifies in practice privatizing them. If we take the example of the water industry, the effect of its privatization - perhaps into the hands of corporate finance capital, a process inaugurated by the Enron Corporation - may be to divert resources away from normal household use, and towards cash-crop agriculture and tourism, major growth sectors under conditions of globalization. The net result would be that, without actually reducing the depletion of the physical environment, entropy would begin increasingly to assert itself within the peripheral social environment, in the form of insecurity and exclusion. Since in this case the periphery serves only passively as a sink, the constraint is its capacity to absorb such costs.

But if we take the standpoint of 'social fuel,' the contribution required from the social periphery appears less passive. Here, we can consider the possibility of some more substantive, structural contribution being extracted from it, which could be exploited as a substitute or complement to an enhanced degradation of the physical environment. Where could the possibility of such a new input arise? I will define this as an enhanced ability to colonize emergence.

\section{THE ROLE OF THE SOCIAL ENVIRONMENT IN FUELLING THE CURRENT REGIME}

In the early post-war period, 'co-opted emergence' occurred in a somewhat limited form. For example, Southern elites had some ability to negotiate the conditions of their dependence, but the emergence of social structures at a grassroots level was not really part of the agenda. This hindered the unfolding of a multi-level, pluralistic experimentation which could potentially provide a much more rich and interesting vocabulary for capitalist regulation.

In principle, the core should always have been able to explore this dimension, but had been afraid to do so. The reasons for this are not hard to find. An important category of emergent movements from below are subversive with respect to the capitalist order. While at one level, emergence implies that they naturally 'happen,' we should not assume their 'spontaneity' to signify a lack of design or strategic consciousness (Guha 1983). Since, as we have seen, information about the future' is a mode of interaction of human systems (Roederer 2003), such movements may well develop information about a counter-systemic future. During the Cold War period in particular, conditions were suitable for this. While it is doubtful that the Soviet version of socialism really constituted a strong enough attractor to rival capitalism, the international political balance did provide a context where grassroots movements could easily develop subversive identities (cf. Scott 1986). The dominant interests were therefore extremely distrustful of anything which was not top-down.

The possibility of overcoming this limitation had been foreshadowed by earlier theories, in particular the work of Gramsci. We can highlight two aspects of his contribution (Gramsci I97I [1927-33]): firstly, the concept of 'hegemony', which we could read from a systems perspective as the ability of the core to impose its attractors upon the development of subordinate systems; and secondly the concept of civil society, which indicates a framework, a multi-layered pluralistic structure, within which this could take place. Suddenly from the r 980 os onward, conditions became propitious for such a development. We might expect it to take two interdependent forms: the 'fuel' required by the core most obviously takes the form of value, but a second, more subtle contribution would be the creation of structure, which increases the capacity of the subordinate system to supply such value. We can reasonably assume that it is more efficient to allow social structure to emerge, rather than designing or imposing it, with all the unnecessary effort and voluntarism which this would imply. 
THE SIGNIFICANCE OF THE NEW MANAGEMENT SYSTEMS IN THE SOCIAL FUELLING PROCESS

In many respects, the pattern and starting point for these changes was the so-called 'new management systems,' a set of practices which became dominant around 1980. In fact, these became the attractor not only within industrial management but for the entire development discourse. Let us first consider their basis within industry.

The background is as follows. Within the workplace, the old orthodoxyoften known as Taylorism and Fordism-had monopolized initiative and information within the technical and managerial staff, viewing any exercise of creativity at the shop floor with extreme distrust; similarly, at the macro level of organization, the firm had typically become a massive enterprise with many subsidiaries, eliminating the market within its boundaries and conducting all transactions administratively. In contrast, the new systems sought at the workplace level to unleash the initiative of the shop floor, an important source of new ideas which could be converted into value, and at the level of the firm to replace direct subsidiaries with an informal, flexible system where contracts are fulfilled by subcontracting. We can consider that these systems showed a new attitude to emergence, and served to address the need for structure, as well as for value. This had always been a latent possibility: operatives have an inherent ability to organize their own work rather than being told what to do. In traditional systems, Chayanov (1966 [1924]) showed how household units organize their labor through 'self-exploitation.' And since, as we have seen, the 'non-core' is a terrain of interaction, where tradition is not simply destroyed but also modified and processed to create new structures, the faculty for self-exploitation could potentially also be unleashed in a modern context.

Do the new management systems genuinely reduce entropy? This is an interesting question. Of course, all management theories (for example, the Taylorist and Fordist ones in their time) have claimed to be 'better' by some neutral criterion of efficiency, and these claims have been widely criticized (Braverman 1974). As Harvey (2000) has pointed out, the natural systemic workings of life itself, whereby everything processes energy in a kind of circuit of reproduction, is subordinated to an external logic: the reproduction-accumulation of capital. Management, as an expression of this, fulfills a very strong function of repression and surveillance (Harvey 2000). The sense of order-as-control is very strong here.

Nevertheless, we cannot dismiss out of hand the notion that the current phase of capitalism has really found ways of minimizing its entropy, through reducing the 'friction' implied in those earlier commandist management proce- dures which not only inhibited emergence but were positively hostile to it. From this follows the assumption that one could, theoretically, design work-organization and mechanical systems along similar principles of minimizing unnecessary dissipation (Dincer 2002). In the sense that this is a reasonable aspiration, not only for capitalism but for wider debates about the rational organization of society, there is something valid in the questions raised here. But there are two issues which it is important not to confuse. The argument that the new structures are a more efficient mode of operation for capitalism is one thing, and may well be partially true. However, we should be extremely wary about extending this in the direction of saying that they are a breakthrough for human society in general, as for example Göran Wall appears to do (Wall 1993). Our argument so far has emphasized that the fundamental criterion of the mode of production is not efficiency in a neutral sense, but efficiency in the interest of accumulation, and there is no reason to expect that it would be any different with the new management systems. Surely, the thermodynamic principles of efficiency are being used as an excuse to smuggle in strategies which merely borrow the appearance of neutrality, and are in reality efficient from a control perspective.

But in relation to the goals of capitalism, there is probably a genuine advantage in thinking systemically, in addressing the need to unleash (and control) emergence. Of course, the old commandism is still present. Indeed, deregulation (which is supposed to be pro-market) has had the effect of removing restrictions on the oligopolistic power of the big organized corporations. World Bank and IMF Structural Adjustment programs have added a further element of agency, obliging developing countries to dismantle any measures which might hinder these predatory actors. Nevertheless, the thing which these commandist actors are presiding over (and from which they seek to appropriate the benefit of value and structure) is a productive system where the scope of emergent, self-engineered relationships is definitely present, and even quite impressive. Probably its central feature is the production chain, whereby small firms respond to orders emanating from the core, for example for components or to fulfill assembly tasks, then typically sub-contract tasks to still smaller firms.

In one sense, these patterns appear to be transitory, galvanized only to respond to a particular demand before fading away. But in reality there is something more permanent underlying this, an adaptive system of networks which acquires a certain stability, while at the same time constantly modifying itself as required. At the most basic level, we find what is perhaps the most interesting example of industrial emergent structure, the phenomenon known as clustering. Nodes develop, grouping producers within a particular geographical area specializing in a certain branch of production (Nadvi and Schmitz I994). The term conjures up an image from astrophysics, but of course since it is a human 
system, the medium of transmitting the 'forces' which generate the clustering is information. Those who lack the information suffer a 'periphery discount' (Steinle and Schiele 2002). Production chains can link together clusters, and in so doing facilitate the self-definition of space at higher levels, for example the 'New Regionalism,' and its manifestation in the 'Pacific basin' (cf. Gereffi 1993; Clark and Chan 1992). Although in one aspect the New Regionalism is political, voluntaristic and institutionalized, this initiative presupposes a reality already partly created by production chains; politics thereby taking hold of and channeling an emergent self-definition of space.

It is clear that the chains can act as a medium for conducting the kind of transfer of order/disorder which we have been discussing in this article. More obviously, this would appear as a fuelling process, a transfer of value upwards, but the systems perspective would highlight also a transfer of entropy downwardsa more profound representation because it pinpoints the fact that what appears superficially as creativity and entrepreneurship may in reality be the absorption of insecurity and risk. This insecurity is the true social sink' into which the quest for capitalist order is dissipated. It exists in two aspects: the increasingly precarious workers and self-exploiting small producers lower down the chain; and the marginalized who are excluded from the formal productive process altogether.

This structure, upon which core order depends, has to be kept in a good state of repair. Various tasks are implied, including the policing of information-flows, for example through the use of intellectual property rights. But most important is to manage peripheral society in such a way as to maintain its contribution as an area into which the core can dissipate. And this brings us back to the issue which is always present somewhere in the background: it is impossible to separate the 'positive' contribution of the periphery from its role as a sink to absorb disorder. And this in turn can never be isolated from the risk of society tipping over into a state where its low order ceases to be self-reproducing.

\section{THE WIDER DEVELOPMENT DISCOURSE}

Like the industrial management systems, the new development discourse which accompanied them is interested in both value and structure. But here, structure has a more autonomous role. Whereas for the management systems, structure and the transfer of value/risk are basically one and the same, in a wider societal context, a contradiction appears. Since the simple extraction of value always carries a risk of undermining the reproduction of society, social structure is required to counteract such a tendency. This might be achieved through the introduction of something which I will term social capital of governance.'

The development discourse accords recognition to a realm of self-organization previously ignored or combated by the modernization perspective, namely the informal economy. The latter is suddenly revealed as a useful agent in reproducing social order, in conducting a simplified version of capital reproduction, which parodies the expanded reproduction of core capital and helps maintain peripheral 'low' order. The work of Hernan de Soto (2002) played a focal role in promoting this approach. For example, by giving the poor land rights, you enable them to use their property as collateral to raise money and start small businesses, thus simultaneously converting 'dead capital' into something active, and promoting a self-maintaining form of social stability. A fashionable embodiment of this approach is the notion of micro-credit: here, a small seed capital is loaned out to finance small projects, repaid and then recycled so that it keeps reproducing itself. Consciously, it is not just the capital which reproduces itself, but also social order. This approach strongly confirms that the 'non-core' is a scene of emergence, where some faculties of self-organization or self-exploitation can be borrowed from tradition and revitalized.

So much for the socio-economic facet of social capital of governance, but it also has a more directly political aspect. The very notion of governance (replacing government) suggests greater complexity. Under the 1945 regime of accumulation (strongly determined by the Cold War), the typical mode of rule in the periphery had been a simple, dictatorial one; in response, a generalized struggle from below demanded democratization (e.g. Anyang' Nyongo 1987). The core in turn responded by aiming to hijack this movement, creating its own attractors to channel it, backed up by material aid to strengthen selectively whatever emergent phenomena in the periphery could be identified as 'best practice.' Central to the discourses has been the notion of 'civil society. The democratization movement threatened to replace the simplified order of the old dictatorships with a more healthy and complex pluralism; arguably the dominant 'civil society' discourse has counteracted this danger, by channeling the political process into a new simplified form. An important example of the agendas which shape this process can be found in William Robinson's (1996) analysis of the role, within United States development sociology, of a concept known as 'polyarchy' If we make a systems-theory reading of polyarchy, it strikingly typifies a peripheral 'low order', a self-reproducing limbo unable to develop either in the direction of a strong state (which might push nationalistic agendas which the core would not like) or into that of the more 'advanced' democracy which the core reserves for itself, or still less into radical, counter-systemic democratic forms.

We have only outlined the control mechanisms in an ideal form. Even while the overall regime remains solid, they are far from foolproof. But a particularly interesting issue, which will form the final part of our inquiry, will be to consider how the social governance structure might behave in the context of a general weakening of the global capitalist IPE during the 'down' phase of a cyclical crisis. 


\section{THE EXHAUSTION OF ROOM TO MANEUVER FOR THE CREATION OF A}

\section{NEW ACCUMULATION REGIME}

Each accumulation regime has a finite developmental potential specific to it. For example, in the case of the post-war regime, social relations in the core became unstable once the Keynesian order had finished consuming the terrain of unemployment. This is why development takes a cyclical form. At some point the current regime will be overtaken by its own specific form of exhaustion. A period of low order associated with the breakdown of its specific relationships would ensue, and then in principle give way to the construction of a new regime. But there would need to be some way, firstly of dissipating the costs of crisis, secondly of fuelling the transition itself, and thirdly of meeting the ongoing accumulation demands of this new regime.

Our assertion is that no subsequent regimes could be fuelled by such a sudden increase of degradation of the physical environment as occurred in 1945. This creates a certain 'ceiling' restricting the room for maneuver, with the implication that future regulation will rely strongly on exporting the effort into the social sphere. But then we encounter an important issue. Whereas the mode of production has been able hitherto to salvage its fundamental rules by discovering new social regimes, a major manifestation of the entropy problem may be that it does not have an inexhaustible set of possibilities for doing so. In explaining this notion, it will be helpful to disaggregate it into three interdependent aspects.

Firstly, there is a certain, perhaps finite, vocabulary of possible developments within the initial rules of the mode of production, which to some extent we can consider to have been immanent within it long before they are actualized as building material for new regimes of accumulation. This is suggested by the fact that we have drawn heavily on theoreticians from early in the imperialist phase of capitalism (Hobson, Naoroji, Gramsci, Luxemburg, Chayanov) who were able to delineate with surprising accuracy forms of organization which revealed their full potential only many decades later. This does not mean that development is predetermined. The circumstances in which these possibilities are activated are not predictable. But a manifestation of the entropy problem would be that once a particular 'card' has been played, it has in some sense been 'used up', and the scope for future development correspondingly reduced. Considered in this way, the success of each regime itself embodies entropy.

In the case of the current regime, there is some sense that the effort required to establish it was so intense as to require the mode of production to play too many of its cards at once. Of course, the contribution of these new ingredients does not cease when they are activated. For example, the developmental potential of transferring manufacturing industry to the periphery, or of co-opting emer- gence through civil society, have not exhausted themselves and will continue to generate order for some time. But they will never again constitute a new input. And if, as seems likely, each regime requires the injection of a fundamentally new dimension of accumulation and/or governance, this is a real problem. To envisage how future regimes might be fuelled one would have to identify fresh possibilities, and this is not easy.

Secondly, let us reconsider Rosa Luxemburg's definition of entropy. Whatever criticisms may be made of her deductions about the nature of social order in the periphery, one profound issue which refuses to go away is the relationship between capitalist entropy and commodification. The notion of a shrinkage of the terrain which is not yet commodified, and hence available for future commodification, is surely still entirely justified. If development were smoothly linear, the mode of production would husband this fuel, consuming it gradually and with circumspection. Instead, because development is lumpy, and because the physical environment could not be depleted as sharply as in 1945, the mode of production has (since about 1980) suddenly burned up too much of its fuel in a very short period, by commodifying almost everything. Future scope is thereby drastically restricted.

Thirdly, there is some sense of an 'arrow of time' in the direction of increasing complexity. The 1980 regime was not just 'another' regime; it was perhaps qualitatively more emergent and less designed than any previous one. This had the enormous advantage of enlisting the periphery to design the structures of its own subordination. The innovatory aspect of the current regime was that, in place of the emergent order occurring through the interaction of simple, statecentric entities (as described in structuralist IR theory-cf. Waltz I979), power could now be exercised through pluralism, through complexity. But the result was a curious hybrid: while order-as-structure is characterized by unprecedented pluralism and complexity, order-as-control remains inherently simple. Now, this raises a very interesting scenario in relation to the structural crisis of the current regime. The 'arrow of time' may make it improbable that complexity and pluralism could be clawed back. But this is surely what the dominant interests will be forced to attempt. In fact, the rise of simplified, militaristic forms of governance since the end of the I990s suggests that this scenario has already begun. The result can only be an immense contradiction between the two definitions of order.

Taking into consideration the above three aspects of the entropy issue, it is hard to escape the conclusion that the resolution of the regime-change problem will be far more difficult than in the past. And since the system has been forced to unleash multi-level peripheral emergence, the question arises how this would react under conditions when the dominant attractors begin to weaken. It can be 
hypothesized that the result might be something we could describe as 'uncontrolled emergence'; or, as Yeats (I963 [I92I]: 2II) expressed it in a poem rich in systems imagery:

Turning and turning in the widening gyre

The falcon cannot hear the falconer

Let us consider more closely the governance problem. One aspect of uncontrolled emergence could be movements by peripheral elites. These arise within what could be considered the 'functional periphery', the regions which perform functions indispensable to core order (e.g. exporting manufactured goods). Normally, they are confined within the 'negotiated dependency' scenarios we discussed earlier. But in a situation of low regime order, elite demands might, while not challenging capitalism as such, tend towards a geographical displacement of the global mode of production away from the historic core. However, the latter controls the military power, and would be unlikely to tolerate this. This would be one form of the problem. The other form could arise within the periphery of the periphery' - countries which are not 'chosen' by uneven development as sites of export promotion, underprivileged regions within any country, and the marginalized populations who are required neither for production nor consumption. These areas could be a scene of unpredictable forms of emergence, which might be destructive, as in the case of deprivation and conflict, but might also be constructive in a subversive sense. Both forms of uncontrolled emergence could be viewed as a challenge to the boundaries which determine core-periphery relations in the IPE: elite movements might for example challenge the knowledge boundary enforced through intellectual property, whereas migration in response to deprivation and conflict would challenge the restrictions to the movement of people which currently fence in the benefits of core order.

The rise of the 'anti-poverty' notion within mainstream development discourses could be seen as a response to this problem. In the sense in which it is used as a strategy for controlling peripheral elites (for example through current World Bank policies) it is somewhat cosmetic, but there is nevertheless a substantive agenda that if Southern states could be forced to divert resources into what is in any case a futile attempt to manage their own poverty, they would be sidetracked from pushing the kind of aggressive national development strategies which would be uncomfortable to the global North. Even more interesting, though, is to consider the significance of the discourse with respect to its direct social engineering role in the marginalized periphery.

The significance of the region of 'tradition' (non-monetary relations) is precisely that it is quite good at absorbing poverty. Correspondingly, as commodification spreads and everything is monetarized, poverty becomes more dif-
Figure 10 - Visual Representation of Sustainable Livelihoods

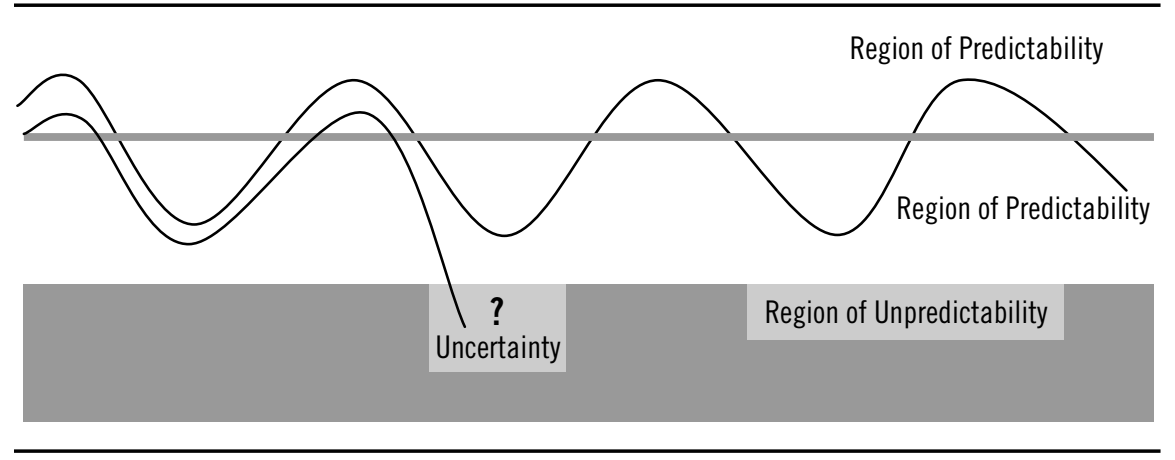

ficult to hide. The dominant discourse certainly has no place for a real structural approach to the causes of poverty, such as those addressed in the 'drain' theory. Nevertheless, there is a structural dimension in the way that it approaches the problem of managing it. The concept of 'sustainable livelihoods' can be taken as an illustration (cf. Meikle et al. 1999). If we analyze this concept systemically, we can see that poor families are considered to fluctuate around a poverty line, and the challenge is to prevent the fluctuations going too far on the downside, where they would disappear off the map (see Figure Io)

If we make a critical analysis of Figure Io, the notion of 'the edge of chaos' springs to mind. There is an area close to the region of unpredictability where cooptable emergence may be particularly intense, in the form of small enterprises, micro-credit etc.; but once the threshold is crossed, forms of emergence may occur which are then difficult to claw back into the orbit of the dominant globalcapitalist attractor. This problem could clearly be intensified in a structural crisis, since the weakening of the hegemonic attractors might set free even established (and at present co-optable) instances of emergence, such as the 'clustering' of small producers, to become part of autonomous strategies. Such uncontrolled emergence would in turn operate as a positive feedback loop to augment the system's instability.

\section{CONCLUSION}

This article has surveyed some areas of literature relevant to a systems-theory reading of the development of the international political economy. It has demonstrated the usefulness of a distinctly social definition of entropy, considered under two aspects: the transfer of order and disorder between core and periphery; and the sense in which a supposedly self-fuelling process of development is actually maintained by colonizing a finite social space, by the exhaustion of future room 
to maneuver. Although social core-periphery transactions are closely intertwined with those involving the physical environment, it is useful to separate the two categories in order to see how regulation-principally expressed in the establishment of regimes of accumulation-may differentially exploit one or the other aspect. The social definition of entropy is a useful tool in generating insights about the current phase which began around 1980, revealing how the latter (constrained by the overall 'ceiling' prescribed by the level of physical-environmental degradation), has been obliged to tap into new forms of regulation drawing on its mode of governance in the social milieu. This in turn poses the entropy problem in a new and sharper form, while also making it difficult to identify a remaining scope for future restructuring.

\section{REFERENCES}

Akerman, Maria. 2003. "What does 'Natural Capital' do? The Role of Metaphor in Economic Understanding of the Environment." Environmental Values I2: 43I-448.

Amin, Samir. 1977. La loi de la valeur et le matérialisme historique. Paris : Éditions de Minuit.

Anyang' Nyong'o, Peter, ed. 1987. Popular Struggles for Democracy in Africa. London: United Nations University.

Baran, Paul A. 1973 [1957]. The Political Economy of Growth. London: Penguin. Barry, Brian. 1998. "Social Exclusion, Social Isolation and the Distribution of Income." CASEpaper I2. London: Centre for Analysis of Social Exclusion (CASE), London School of Economics.

Biel, Robert A. 2000. The New Imperialism: Crisis and Contradictions in North-South Relations. London: Zed Books.

Braverman, Harry. 1974. Labor and Monopoly Capital. New York: Monthly Review.

Bunker, Stephen G. 1985. Underdeveloping the Amazon: Extraction, Unequal Exchange and the Failure of the Modern State. Chicago, IL: University of Chicago Press.

Byron, Michael P. 200I. "Modeling the Global International System: Logical Consistency with Theory, Internal Self-consistency and Empirical Falsifiability." Journal of Sociocybernetics 2(I): 9-3I.

Caldwell, M. N.d. [I972]. The Energy of Imperialism, and the Imperialism of Energy. London: School of Oriental and African Studies.

Césaire, Aime. 1972 [1955]. Discourse on Colonialism. New York: Monthly Review.

Chayanov, Alexander V. 1966 [1924]. On the Theory of Peasant Economy. Manchester, England: Manchester University Press.

Clark, Cal, and Steve Chan, eds. 1992. The Evolving Pacific Basin in the Global Political Economy. Boulder, CO: Lynne Rienner.

Curtin, Philip D. 1965. The Image of Africa: British Ideas and Action, 1780-1850. London: Macmillan.
Daly, Herman E., and John Cobb. 1989. For the Common Good. Boston, MA: Beacon Press.

Day, Richard B. 1981. The Crisis and the Crash. London: NLB.

De Soto, Hernando. 2000. The Mystery of Capital: Why Capitalism Triumphs in the West and Fails Everywhere Else. New York: Basic Books.

Dincer, Ibrahim. 2002. "The Role of Exergy in Energy Policy Making." Energy Policy $30(2) \div 137-149$.

Dos Santos, Theotonio. I970. "The Structure of Dependency." American Economic Review 60 (2): 23I-236.

Duménil, Gerard, and Dominique Lévy+ 2002. "The Profit Rate: Where and How Much Did it Fall? Did it Recover? (USA 1948-2000)" Review of Radical Political Economics 34(4): 437-46I.

Fanon, Franz. 1965 [1961]. The Wretched of the Earth. London: Macgibbon and Kee.

Frank, Andre G. 1978. World Accumulation, 1492-1789. London: Macmillan. . 1979. Dependent Accumulation and Underdevelopment. New York: Monthly Review Press.

Gale, Fred P. 1998. "Theorizing Power in Ecological Economics." Ecological Economics 27: I3I-I38.

Georgescu-Roegen, Nicholas. 1975. "Energy and Economic Myths." Southern Economic Journal 4I(3):347-38I.

Gereffi, Gary. 1993. "Global Sourcing and Regional Divisions of Labor in the Pacific Rim." In What is in a Rim?: Critical Perspectives on the Pacific Rim Idea, edited by Arif Dirlik. Boulder, CO: Westview.

Goldman, Michael. 2005. Imperial Nature: The World Bank and Struggles for Social Justice in the Age of Globalisation. New Haven, CT: Yale University Press.

Gramsci, Antonio. 197I [1927-33]. Selections from the Prison Notebooks. London: Lawrence and Wishart.

Guha, Ranajit. I983. Elementary Aspects of Peasant Insurgency in Colonial India. Delhi: Oxford University Press.

Hardin, Garrett. I968. "The Tragedy of the Commons." Science I62: I243-I248.

Hartsock, Nancy. 1983. Money, Sex and Power: Toward a Feminist Historical Materialism. Boston, MA: Northeastern University Press.

Harvey, David. 2000. Spaces of Hope. Berkeley, CA: University of California Press.

Hayek, Friedrich von. 1973. Law, Legislation and Liberty: A New Statement of the Liberal Principles of Justice and Political Economy. London: Routledge and Kegan Paul.

Hobson, J. A. I902, Imperialism: A Study. London: G. Allen and Unwin.

Hornborg, Alf. 200I. The Power of the Machine: Global Inequalities of Economy, Technology, and Environment. Lanham, MD: Rowman \& Littlefield.

Hegel, Georg F. W. I969 [I8I2]. Hegel's Science of Logic, translated by A. V. Miller. London: G. Allen and Unwin.

James, C. L. R. I980 [1938]. The Black Jacobins. Revised edition. London: Allison and Busby. 
Kay, J.J. 199I. "A Non-equilibrium Thermodynamic Framework for Discussing Ecosystem Integrity." Environmental Management 15(4): 483-495.

Keynes, John M. 1919. The Economic Consequences of the Peace. London: Macmillan. Kim, Young-Ho. 1987. "Towards an Articulation of Dependency and Development Paradigms: Development of Semi-Development in the Korean Economy." In Dependency Issues in Korean Development, edited by Kyong-Dong Kim. Seoul, South Korea: Seoul National University Press.

Leffler, Melvin P. 1994. "National Security and United States Foreign Policy." In Origins of the Cold War, edited by Melvin P. Leffler and David S. Painter. London: Routledge.

Lenin, Vladimir I. 196I [1915]. "On the Question of Dialectics." In Collected Works, edited by V. I. Lenin. Moscow: Progress Publishers.

Lévi-Strauss, Claude. 1958. Anthropologie structurale. Vol. I. Paris: Plon.

Lewis, W. Arthur. 1958. "Economic Development with Unlimited Supplies of Labour." In The Economics of Underdevelopment, edited by Amar N. Agarwala and S. P. Singh. Delhi, India: Oxford University Press.

Lipietz, Alain. 1987. Miracles and Mirages: The Crisis of Global Fordism. London: Verso.

Luxemburg, Rosa. 195I [19I3], Die Akkumulation des Kapitals -ine Beitrag zur Ökonomischen Erklarung des Imperialismus. Berlin: Paul Singer; and English translation of the above, London: Routledge and Kegan Paul.

Meadows, Donella, et al. 1972. The Limits to Growth. London: Earth Island.

Meikle, Sheilah, Tamsin Ramasut, and Julian Walker. 1999. "Sustainable Urban Livelihoods: Concepts and Implications for Policy." London: Development Planning Unit.

Merchant, Carolyn. 1990. The Death of Nature. New York: Harper.

Nadvi, Khalid, and Hubert Schmitz. 1994. "Industrial Clusters in Less Developed Countries: Review of Experiences and Research Agenda." Paper presented at the Institute of Development Studies, Sussex, England. Discussion Paper no. 339.

Naoroji, Dadabhai. 1962 [1901]. Poverty and Un-British Rule in India. Delhi, India: Oxford University Press.

Podobnik, Bruce. 2002. "Global Energy Inequalities: Exploring the Long-Term Implications." Journal of World-Systems Research 8(2):252-274. http://jwsr.ucr.edu/archive/vol8/number2/pdf/jwst-v8n2-podobnik.pdf

Prew, Paul. 2003. "The 2ist Century World-Ecosystem: Systemic Collapse or Transition to a New Dissipative Structure?" In Emerging Issues in the 21st Century World-System. Volume II, edited by Wilma A. Dunaway. Westport, CT: Praeger Publishers.

Raskin, Paul, et al. 2002. Great Transition: The Promise and Lure of the Times Abead. Boston, MA: Stockholm Environment Institute and Global Scenario Group.

Robinson, William L. 1996. Promoting Polyarchy: Globalisation, US Intervention and Hegemony. Cambridge, England: Cambridge University Press.

Rodney, Walter. 1972. How Europe Underdeveloped Africa. London: Boglel'Ouverture.
The Interplay between Social and Environmental Degradation

Roederer, Juan G. 2003. "On the Concept of Information and its Role in Nature." Entropy 5:3-33.

Rostow, Walt W. 1960. The Process of Economic Growth. Second edition. Oxford: Clarendon.

Scott, James C. 1986. "Everyday Forms of Peasant Resistance." In Everyday Forms of Peasant Resistance in South-East Asia, edited by James C. Scott and Benedict J. Tria Kerkvliet. London: Frank Cass.

Sibley, David. I995. Geographies of Exclusion: Society and Difference in the West. London: Routledge.

Sprout, Harold, and Margaret Sprout. 1968. "An Ecological Paradigm for the Study of International Politics." Research Monograph No. 30. Princeton, NJ: Center for International Studies.

Steinle, Claus, and Holger Schiele. 2002. "When Do Industries Cluster? A Proposal on How to Assess an Industry's Propensity to Concentrate at a Single Region or Nation." Research Policy No. 3I.

Wall, Göran. 1993 "Exergy, Ecology and Democracy: Concepts of a Vital Society or a Proposal for an Exergy Tax." Paper presented at the International Conference on Energy Systems and Ecology, Krakow, Poland. http://exergy.se/goran/eed/

Waltz, Kenneth. 1979. Theory of International Politics. Reading, England: AddisonWesley.

Waring, Marilyn, I989. If Women Counted. London: Macmillan.

World Resources Institute. 2003. "Energy Consumption by Economic Sector." EarthTrends Data Tables, Washington DC. http://earthtrends.wri.org/pdf library/data tables/ene5 2003.pdf

Yeats, William B. I963 [I92I]. "The Second Coming." In Michael Robartes and the Dancer in Collected Poems of W.B. Yeats. London: Macmillan.

von Tunzelmann, Nick. 2003. "Historical Coevolution of Governance and Technology in the Industrial Revolutions." Structural Change and Economic Dynamics I4: $365-384$.

Zwick, Martin. N.d. "Incompleteness, Negation, Hazard: On the Precariousness of Systems." Paper presented at Portland State University, Portland, Oregon. 